\title{
Impact of empowerment, flexibility and trust on women's access to senior positions in RMG industry of Bangladesh
}

\begin{abstract}
Accessing in senior positions of organisations is always challenging for women especially in developing countries. Although several studies in the past have helped explain the impact of some significant variables for women access to senior positions, not many studies examined the effects of certain factors such as empowerment, flexibility and trust on women's access to senior positions in the Ready Made Garments (RMG) industry. Thus, the aim of the study is to examine the impact of empowerment, flexibility and trust in the RMG industry where more than $90 \%$ of workers are women. This study employed a convenience sampling method to select 200 female respondents working in different positions RMG industry in Dhaka, Bangladesh. The finding reveals that empowerment and trust have the significant impact on women's access to the senior positions in RMG organizations in Bangladesh. However, findings shows that flexibility has no significant impact on women' access to senior positions in RMG organizations in Bangladesh. Future researches can be conducted to include more variables and respondents.
\end{abstract}

Keyword: Ready made garments; Industry 